\title{
ENSINANDO LUTAS NA ESCOLA: PERCEPÇÕES E EXPECTATIVAS DE DIRIGENTES DO ENSINO FUNDAMENTAL
}

\section{TEACHING MARTIAL ARTS IN SCHOOLS: PERCEPTIONS AND EXPECTATIONS OF ELEMENTARY SCHOOL LEADERS}

\author{
Alba lara Cae Rodrigues* \\ albaicrodrigues@hotmail.com \\ Marcelo Moreira Antunes ** \\ antunesmm@gmail.com
}

\footnotetext{
* Universidade Estadual de Campinas, São Paulo - Brasil ** Universidade Federal Fluminense. Rio de Janeiro - Brasil
}

\section{Resumo Abstract}

O objetivo deste estudo é compreender as concepções sobre o perfil do professor de luta pelos dirigentes das escolas de Ensino Fundamental I do município de Jaguariúna (SP). Entrevistas semiestruturadas com 30 líderes de 15 escolas públicas e privadas foram coletadas nesta intervenção. A análise dos dados permitiu identificar aspectos importantes do perfil desejado desses profissionais por meio de categorias de base provenientes dos discursos dos dirigentes. Portanto, como resultado, identificamos a perspectiva dos dirigentes escolares sobre as lutas como um objeto de conhecimento desejado para este contexto, com preocupações relacionadas à aspectos pedagógicos e a profissionalização dos profofessores de lutas. Acreditamos que a partir dos resultados aqui apontados, novos estudos possam fornecer modelos pedagógicos com o objetivo de formação profissional para esses professores, a fim de garantir uma adaptação para incluir esse objeto de conhecimento na escola, seja na educação física escolar ou em projetos extracurriculares.

PALAVRAS CHAVE: Artes marciais; Educação física escolar; Perfil profissional.

The objective of this study is to understand the conceptions of elementary school leaders about the profile of martial arts teachers in the city of Jaguariúna (SP). Semi-structured interview with 30 leaders from 15 public and private schools were collected in this intervention. The data analysis provided the identification of important aspects of the desiered profile of these professionals through categories of the speaches of the leaders. This research brought insights on how school leaders view martial arts as a desired content for this context, thus with concernes on some pedagogical aspects and professionalization of these teachers. With these results, we believe that new studies can provide pedagogical models with the aim of professional training for these teachers to ensure an adaptation to include this content in school, whether in physical education or extracurricular projects.

KEYWORDS: Martial arts; Physical education; Professional profile.

\section{Introdução}

As lutas, pelo potencial transformador que possuem, podem influenciar significativamente o desenvolvimento do indivíduo por diversos fatores, como o autoconhecimento, saúde e sociabilidade. Na atualidade, o desenvolvimento das lutas permite 
que sua prática se realize em diferentes contextos (lazer, esporte, educação e saúde) por diversos personagens, como crianças, adolescentes, idosos, mulheres e pessoas com deficiência. Seu ensino em ambiente escolar se configura como uma importante unidade temática na ampliação do conhecimento da cultura corporal, presente na civilização humana desde seus primórdios (BRASIL, 2018), aspectos que permitem múltiplas possibilidades deste objeto de conhecimento, favorecendo assim o desenvolvimento integral dos praticantes. Especificamente na esfera educacional as lutas possuem um grande leque de possibilidades para oferecer aos alunos um desenvolvimento saudável, vinculado à compreensão da prática regular de atividade física. Possibilitam o aprimoramento das relações sociais, uma vez que para a sua prática há a necessidade da relação com o outro, além do desenvolvimento do apreço às regras e a valores como cooperação, solidariedade e disciplina, uma vez que o ensino das lutas não se restringem as ações técnicas de ataque e defesa.

Segundo Antunes (2016a), as lutas abordadas na dimensão da educação, formal ou informal, carregam um conteúdo significativo para o desenvolvimento dos indivíduos, quando associado à adequada condução dada pelo professor. A ação pedagógica planejada para o trabalho com esse objeto de conhecimento deve partir do pressuposto da adequada formação do professor para o exercício da docência. Na literatura encontramos algumas pesquisas que tratam sobre a formação dos profissionais das lutas no sentido acadêmico (CORREIA; FRANCHINI, 2010; GOMES; AVELAR-ROSA，2012; RUFINO; DARIDO, 2015), discutindo a qualidade dessa formação e o perfil dos professores que atuarão na escola, além dos requisitos exigidos por federações e confederações para atuação como treinador (DRIGO, et al., 2011). Este é um tema ainda longe de se esgotar, frente a contínua transformação dos contextos e o surgimento de novos praticantes com características e subjetividades distintas. Portanto, a prática das lutas deve ser relacionada às dimensões filosóficas, sociais e pedagógicas buscando ampliar a compreensão dos que ensinam e praticam, favorecendo a prática responsável, consciente e de forma contextualizada segundo as demandas sociais (ANTUNES, 2016a).

Nesse sentido, a incorporação da dimensão pedagógica no ensino das lutas tem como foco principal os alunos, e quando orientada por profissionais capacitados que objetivam um trabalho direcionado ao processo de ensino e aprendizagem, tem um papel importante no desenvolvimento integral dos discentes. Corroborando com isso Correia e Franchini (2010), afirmam que é necessária uma transformação didática e pedagógica na edificação dos fazeres e saberes escolares, para que seja então possível a inserção do profissional de diversas atividades na escola.

Na perspectiva do ensino das lutas como um objeto de conhecimento educacional e da importância do professor no processo de ensino e aprendizagem, o objetivo deste trabalho é compreender as concepções sobre o perfil do professor de luta pelos dirigentes das escolas de Ensino Fundamental 1, do município de Jaguariúna (SP). Espera-se que com os resultados aqui apesentados possamos compreender qual é a percepção de dirigentes de escolas sobre os professores de lutas na atualidade. Em outra perspectiva, a partir da compreensão de características desejados para estes profissionais, para atuação em ambiente escolar, pretendemos favorecer estudos voltados à formação e profissionalização de professores de lutas para que possam desenvolver projetos mais adequados para este ambiente. Ainda, 0 
levantamento dessas opiniões possibilita voltar o olhar para a demanda do mercado de trabalho, no sentido do que é esperado em relação às pessoas que atuam nessas atividades. Dessa forma, a ideia de se traçar o perfil desse profissional para atender as perspecivas em um amibiente escolar, pode auxiliar o planejamento e aprimoramento de processos de formação inicial e continuada. Assim, planejamos responder com esta pesquisa três perguntas: Quais as características que dirigentes de escolas de ensino fundamental 1 acreditam que os professores de lutas apresentam na atualidade? Quais as características que os dirigentes de escolas apontam como importantes para que esses profissionais possam trabalhar no ambiente escolar? Quais as características mais importantes a serem desenvolvidos em docentes de lutas quando se pensa na atuação no ambiente escolar?

\section{Método}

Essa pesquisa qualitativa caracteriza-se como descritiva, com o seu valor baseado na resolução de problemas e práticas melhoradas a partir de observações, análise e descrições objetivas e completas (THOMAS; NELSON; SILVERMAN, 2012). O método exploratório utilizou a técnica survey, objetivando determinar práticas ou opiniões dos dirigentes das escolas a partir de entrevistas semiestruturadas.

A escolha do Ensino Fundamental 1 justifica-se pelo predomínio da faixa etária favorável à iniciação esportiva. Essa iniciação na infância leva à reflexão da organização do processo, da dimensão do conteúdo, até o sentido de finalidade atribuído ao esporte com uma visão pedagógica (CAVAZANI et al., 2016). A facilidade de acesso e abertura ao diálogo, juntamente com o interesse dos dirigentes sobre o tema foram fatores importantes na escolha pelo município de Jaguariúna (SP), se constituindo como uma seleção amostral por conveniência ou não-probabilistica (THOMAS; NELSON; SILVERMAN, 2012). Participaram da amostra pessoas que ocupavam os cargos de coordenação pedagógica e direção de todas as unidades escolares com ensino fundamental 1 do Município.

\section{II.I. Contexto}

Esse estudo foi realizado em todas as 15 escolas com ensino fundamental 1 de Jaguariúna (11 públicas e quatro particulares). Apenas três delas têm capoeira como atividade extracurricular, sendo que duas são particulares. Este dado demostra que, embora exista interesse pelo tema e sua inserção na escola, ainda há baixa ocorrência nesses espaços.

\section{II.II. Participantes}

Participaram do estudo 15 coordenadoras pedagógicas, 14 diretores e uma vicediretora. Das 15 coordenadoras, 14 possuem formação em pedagogia, além de outras graduações. Nove coordenadoras possuem pós-graduação, oito delas em psicopedagogia. Seis coordenadoras atuam na escola de três a dez anos, cinco de 11 a 20 anos e quatro de 21 a 30 
anos. Todos, exceto uma diretora, apresentam formação em pedagogia. Seis deles possuem pós-graduação em psicopedagogia. Nove diretores atuam na escola entre 10 a 15 anos, três entre 21 a 30 anos, dois atuam há 34 e 46 anos e a vice-diretora atua há 25 anos.

\section{II.III. Procedimentos}

A partir do contato com o Secretário de Educação do Município de Jaguariúna foi realizado um levantamento de todas as escolas públicas com ensino fundamental 1 e identificação de seus responsáveis. As escolas particulares foram identificadas pela consulta em lista telefônica e internet. Uma carta de autorização foi assinada pelo Secretário e apresentada em todas as escolas publicas em uma visita preliminar. O contato com cada dirigente foi feito previamente para agendamento das entrevistas. Todos os responsáveis assinaram cartas autorizando a realização da pesquisa em seus estabelecimentos e todos os entrevistados assinaram um termo de consentimento livre e esclarecido. Cabe destacar que esta pesquisa respeitou os critérios expostos pelas Resoluções CEP n466/12 e n510/2016 do Conselho Nacional de Saúde e que o projeto está registrado sob o número CAAE: 42623514.6.0000.5404, obtendo parecer de aprovação sob o n¹004967.

\section{II.IV. Instrumento}

$O$ roteiro de entrevista semiestruturada é composto de 10 questões. As primeiras quatro perguntas foram referentes à caracterização demográfica dos dirigentes (formação acadêmica, cargo na escola, tempo de atuação no ambiente escolar, idade e sexo). As outras seis perguntas foram referentes ao perfil dos profissionais de lutas no ambiente escolar e sobre este objeto de conhecimento e seus benefícios, tais como: Na escola há ensino de lutas e qual modalidade? Qual é a sua opinião em relação à inserção das lutas no ambiente escolar? 0 Sr.(a) acredita que as lutas possam trazer benefícios no desenvolvimento dos alunos? Se sim quais? Qual é a sua opinião em relação aos professores de lutas na atualidade? Qual é o perfil e as características que acharia ideal para que um professor de lutas possa se inserir no ambiente escolar? Como imagina que essa inserção deveria ser feita?

\section{II.V. Análise dos dados}

As entrevistas foram transcritas e analisadas pelo método Análise de Conteúdo definido por Bardin (2011) como um conjunto de técnicas de análises composto de procedimentos objetivos e sistemáticos na descrição dos conteúdos e na criação de categorias e subcategorias de análise. Também com função de explorar o material coletado para descoberta de novos elementos e para o surgimento de hipóteses, que sirvam de diretrizes no encaminhamento da pesquisa.

\section{Resultados}

Com base nas entrevistas realizadas com os participantes do estudo, dois aspectos de 
análise foram identificados: Percepção das características dos profissionais de lutas que ensinam na atualidade e o Perfil desejado para atuação na escola. O primeiro apresenta opiniões sobre certas características, favoráveis e desfavoráveis, dos profissionais responsáveis pelo ensino das lutas que atuam em diferentes ambientes. Nesse sentido, os dirigentes expressaram suas percepções sobre como acreditam que esses profissionais trabalham hoje em dia e características consideradas importantes na formação das crianças. Essas opiniões foram agrupadas em três categorias: a) Neutro, sem conhecimento ou opinião; b) Características favoráveis dos profissionais no ensino das lutas e c) características desfavoráveis dos profissionais no ensino das lutas, com suas respectivas subcategorias, totalizando 40 ocorrências (Quadro I).

Quadro I - Percepção das características dos professores de lutas

\begin{tabular}{|c|c|c|c|}
\hline Categorias & Subcategorias & Ocorrência & $\%$ \\
\hline Neutro & Sem conhecimento ou opinião. & 5 & 12,5 \\
\hline \multirow{5}{*}{$\begin{array}{c}\text { Características } \\
\text { favoráveis dos } \\
\text { profissionais no ensino } \\
\text { das lutas }\end{array}$} & $\begin{array}{l}\text { Possuem pedagogia e didática } \\
\text { apropriada, trabalho com o } \\
\text { comportamento das crianças e têm } \\
\text { psicologia para lidar com as faixas } \\
\text { etárias. }\end{array}$ & 8 & 20,0 \\
\hline & $\begin{array}{l}\text { Transmitem respeito, são éticos, } \\
\text { equilibrados, disciplinados, educados e } \\
\text { impõem regras. }\end{array}$ & 6 & 15,0 \\
\hline & $\begin{array}{l}\text { Buscam o melhor, são comprometidos } \\
\text { e gostam de crianças. }\end{array}$ & 5 & 12,5 \\
\hline & Auxiliam outros professores. & 2 & 5,0 \\
\hline & São graduados em Educação Física. & 2 & 5,0 \\
\hline \multirow{4}{*}{$\begin{array}{c}\text { Características } \\
\text { desfavoráveis dos } \\
\text { profissionais no ensino } \\
\text { das lutas }\end{array}$} & $\begin{array}{l}\text { Falta pedagogia, didática, metodologia, } \\
\text { capacitação para abordar os alunos e } \\
\text { ensinar a luta. }\end{array}$ & 5 & 12,5 \\
\hline & $\begin{array}{l}\text { Estimulam a competitividade, falta } \\
\text { ética, direcionam para violência, muito } \\
\text { rígidos e doutrinam. }\end{array}$ & 5 & 12,5 \\
\hline & Dificuldade em fazer registros. & 1 & 2,5 \\
\hline & Falta conhecer o cotidiano da escola. & 1 & 2,5 \\
\hline Total & & 40 & 100 \\
\hline
\end{tabular}

Fonte: Dados da pesquisa

O segundo aspecto de análise apresenta o perfil mais adequado dos profissionais de 
lutas para atuarem no ambiente escolar, segundo a opinião dos dirigentes, buscando atingir o objetivo pedagógico das escolas. As ocorrências, que somaram 104, foram divididas em quatro categorias: a) Relacionamento com os alunos; b) Características do profissional; c) Formação profissional e; d) Relação com a escola. As categorias apresentam subcategorias provenientes da análise dos conteúdos nas entrevistas (Quadro II).

Quadro II - Perfil desejado do professor de lutas para atuar na escola

\begin{tabular}{|c|c|c|c|}
\hline Categorias & Subcategorias & Ocorrência & $\%$ \\
\hline \multirow{3}{*}{$\begin{array}{l}\text { Relacionamento } \\
\text { com os alunos }\end{array}$} & $\begin{array}{l}\text { Saber lidar com o aluno, ter controle, gostar } \\
\text { de crianças, diálogo aberto com os alunos } \\
\text { (proximidade) e paciência. }\end{array}$ & 27 & 26,0 \\
\hline & $\begin{array}{l}\text { Passar valores (cidadania, respeito, disciplina, } \\
\text { socialização), não direcionar para a violência } \\
\text { (coibir), conduzir o poder que terão da luta. }\end{array}$ & 10 & 9,6 \\
\hline & $\begin{array}{l}\text { Relação com o ensino e aprendizagem, } \\
\text { conhecer o contexto social, saber diferenciar } \\
\text { amizade das atitudes profissionais, auxiliar no } \\
\text { desenvolvimento global e estimular o lúdico. }\end{array}$ & 7 & 6,7 \\
\hline \multirow{3}{*}{$\begin{array}{l}\text { Características } \\
\text { do profissional }\end{array}$} & $\begin{array}{l}\text { Ser ético, ter coesão, coerência, bom senso, } \\
\text { ser flexível, ser educado e ter princípios. }\end{array}$ & 12 & 11,5 \\
\hline & $\begin{array}{l}\text { Impor regras, ter liderança, autoridade, saber } \\
\text { falar sim e não, ter escolha da faixa etária, e } \\
\text { ser mediador entre a ação do esporte e a } \\
\text { prática. }\end{array}$ & 8 & 7,7 \\
\hline & $\begin{array}{l}\text { Se preocupar com o social (como vai ensinar } \\
\text { para a vida), saber que está lidando com } \\
\text { pessoas (em formação), ter responsabilidade e } \\
\text { estabelecer metas e objetivos a serem } \\
\text { atingidos com aluno. }\end{array}$ & 8 & 7,7 \\
\hline
\end{tabular}




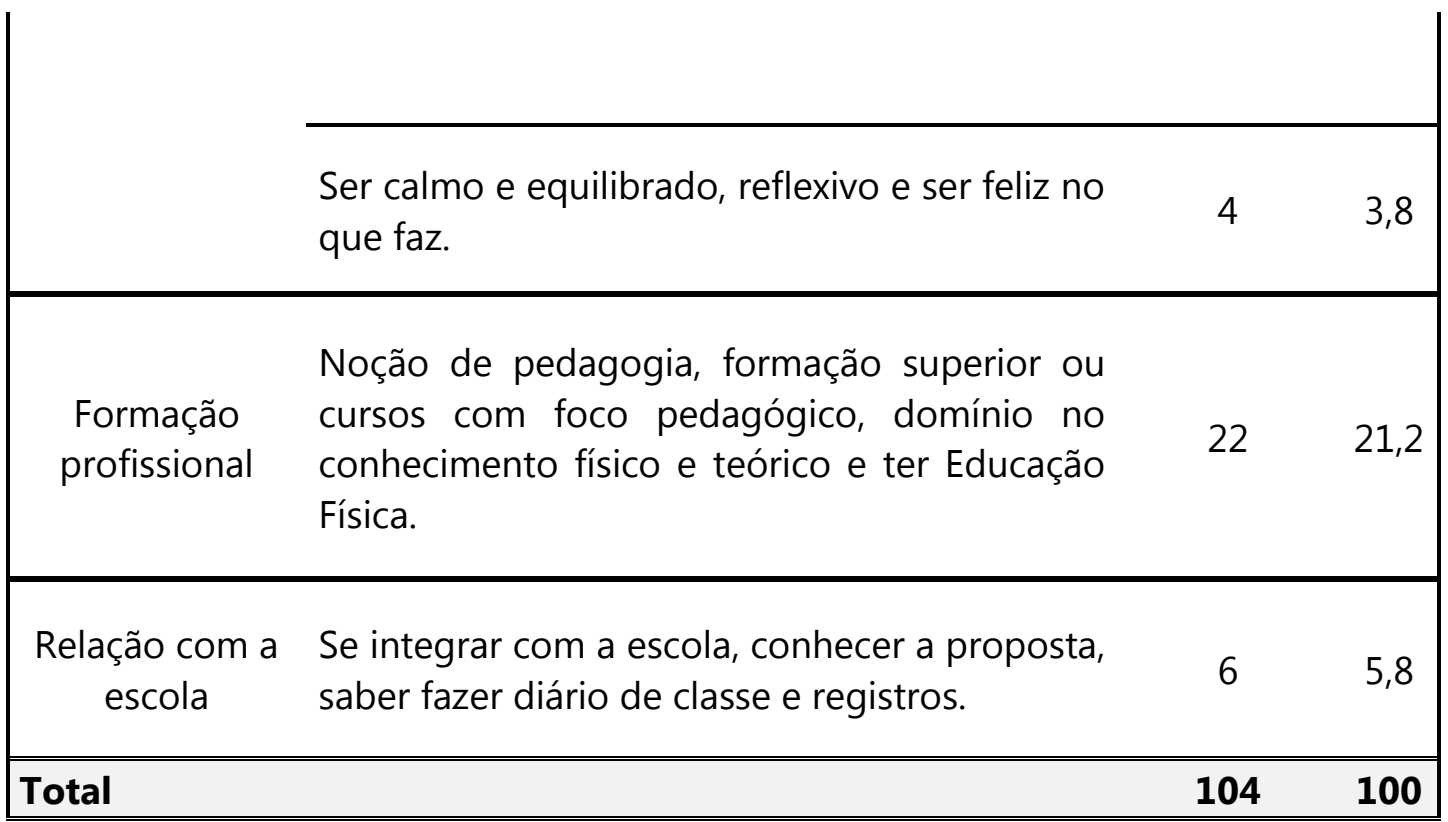

Fonte: Dados da pesquisa

\section{Discussão}

Inicialmente, a percepção dos dirigentes das escolas quando opinam sobre os professores de luta, desvela, opiniões proveniente dos contextos sociais e midiáticos (senso comum), tais como, em seu aspecto positivo, o impacto dessas práticas no comportamento e na disciplina dos alunos, e em seu aspecto negativo a competitividade exagerada e violência e a falta de formação adequada (Quadro I). Nesse sentido, o foco volta-se à necessidade de um dialogo mais amplo e aprofundado sobre os reais significados e possibilidades da prática das lutas em ambiente educativo formal e não formal (ANTUNES, 2016c), para possibilitar a democratização destes conhecimentos, favorecendo, ainda mais as demandas atuais por tais práticas. Além disso, o diálogo proporciona novas reflexões para que profissionais possam melhor se adequar ao contexto escolar. O professor desempenha um papel fundamental como mediador no processo de ensino e aprendizagem. Quando pensamos na prática, na perspectiva da pedagogia do esporte, o professor deve buscar organizar, sistematizar, aplicar e avaliar a natureza da intervenção realizada (REVERDITO, SCAGLIA, PAES, 2013). Portanto, devemos considerar a vivência dos alunos nas lutas, com atenção às suas potencialidades $e$ aspectos educacionais contidos nos procedimentos pedagógicos que os leva a refletirem sobre suas práticas e atitudes (BREDA et al., 2010).

O principal elemento apresentado pelos dirigentes, em ambos os quadros é a relação do ensino das lutas com a dimensão pedagógica. No Quadro I, nas características favoráveis atribuídas aos profissionais, afirmam que os professores possuem pedagogia e didática apropriada, trabalham os aspectos comportamentais e têm psicologia para lidar com diferentes faixas etárias (oito das 23 ocorrências dessa Categoria). A formação em pedagogia e especialização em psicopedagogia para quase a totalidade das participantes contribuiu para as reflexões e proposições sobre a importância da incorporação da prática pedagógica, como uma das características fundamentais na formulação do perfil do profissional de lutas na escola. Diversos autores sinalizam a importância do aspecto pedagógico no ensino das lutas, 
sobretudo, na ampliação das potencialidades do conteúdo educacional (ANTUNES, 2016c; LOURDES, 2014; LOURENÇO FILHO, 2013; PAES et al., 2016; RUFINO; DARIDO, 2015).

Quando tratam das características desfavoráveis desses profissionais, apontam a falta de pedagogia, didática, metodologia, capacitação para abordar os alunos e ensinar a luta (cinco das 12 ocorrências dessa Categoria). Verificamos este aspecto relacionado aos profissionais que atuam na escola em geral, no depoimento de uma coordenadora:

Falta um pouco de metodologia. Mas isso não é uma questão só do professor de lutas. Porque com a nossa formação inicial, quem cursa pedagogia sabe que peca um pouco no processo de ensino, aprendizagem e didática. Então, acho que isso é algo amplo. [...] Então se direcionasse um pouquinho mais a abordagem desse profissional para com os alunos, eu acho que a coisa fluiria melhor.

Nas considerações do perfil formulado como adequado aos profissionais das lutas, na Categoria relacionamento com os alunos, observa-se 27 (26\%) das ocorrências totais, referentes ao saber lidar com as crianças, ter controle, gostar de crianças, diálogo aberto, proximidade com os alunos e paciência (Quadro II). Lourdes (2014) destaca que quem ensina lutas deve ter condições de inserir a criança nesse conhecimento de forma gradual, respeitando uma progressão pedagógica pensada para esse público, confirmando que as preocupações dos dirigentes vão ao encontro do que a literatura sinaliza como importante para esses profissionais na escola. Para que o ensino das lutas seja diferenciado é necessário organizá-lo de modo que o aluno possa atingir a aprendizagem no seu próprio caminho e no seu ritmo (OLIVIER, 2000). Na literatura encontramos autores que propõe sistematização das lutas há algum tempo, (ESPARTERO, 1999; GOMES, et al., 2010; AVELAR-ROSA, et al., 2015; RUFINO; DARIDO, 2015; KOZUB; KOZUB, 2004).

Tratando-se da formação profissional, todas as ocorrências referem-se à noção de pedagogia para lidar com os alunos, à formação superior em cursos com foco pedagógico, embasamento teórico, além do conhecimento físico e técnico. Nesse caso, em relação a formação e a dimensão pedagógica, Lourenço Filho (2013), afirma a necessidade de uma qualificação contínua na formação e na prática pedagógica dos professores de lutas no sentido de aprimorar seu exercício docente, promovendo assim, benefícios mútuos aos professores e praticantes. Acreditamos que essa pedagogia inclusiva implica que o professor tenha conhecimento e prática pedagógica para lidar com as diferenças. Um dos principais desafios nesse sentido é a superação de um modelo educacional que considera o aluno como reprodutor de um conhecimento imutável e um sujeito quase sem individualidade.

Enfim, o fator pedagógico domina as expectativas sobre a qualificação do profissional de lutas para que sua inserção no ambiente escolar cumpra os objetivos desejados e estabelecidos pelos dirigentes, exemplificado pela resposta de uma coordenadora: 
Então, o perfil dele, [...] tem que ter paciência, tem que saber lidar com a criança, tem que ter um bom envolvimento e gostar de criança. Porque para ensinar criança é mais complicado do que adulto, tem momento que a criança tá um pouco desanimada, não quer participar, então esse jogo de cintura do professor é importante.

Ainda, segundo um diretor:

hoje se exige que ele tenha uma formação acadêmica e isso vai dar ferramentas pra ele. Utilizar melhor essas ferramentas em benefício do aluno, o aluno sente isso pela própria didática do professor. Eu acho que [...] ele tem que ter uma linguagem pedagógica pra se comunicar. Comunicação é fundamental. Com esse argumento enfatizam a dificuldade do aluno na interpretação de texto, e daquilo que o professor está dizendo, como atribuições da parte pedagógica, da mesma forma importante.

Também, com a afirmação de outra coordenadora:

Para o professor se inserir no ambiente escolar ele tinha que ter alguma noção de pedagogia, então fazer algum curso voltado pra criança, mas não na área de lutas, ou na área de psicologia. Não estou dizendo uma graduação, aí seria perfeito, mas, pelo menos algum curso sobre afetividade, sobre as fases de desenvolvimento da criança, entender de criança.

O aspecto afetivo ligado a transmissão de valores aos alunos, efetivado no ensino das lutas é outro importante elemento considerado, tanto nas características favoráveis (Quadro I), quanto no perfil profissional projetado pelos dirigentes (Quadro II). Valores como cidadania, respeito, disciplina e socialização, coibindo os aspectos relacionados à violência, conduzindo de forma positiva o poder que terão com a luta. Para Carreiro (2011), espera-se uma intervenção ativa dos professores para ressignificação do papel das lutas nas dimensões atitudinais ligadas aos valores no contexto educacional, com valorização de atitudes de não violência, respeito, resolução de problemas através do diálogo, justiça e solidariedade. Essa aprendizagem pode ser alcançada com debates, discussões, reflexões e vivências práticas, para que as lutas possam contribuir para a formação dos cidadãos, integrando a esfera da cultura corporal. Nesse sentido, Rodrigues et al. (2017) verificaram em seu estudo, também com dirigentes escolares, que as lutas devem trazer benefícios como os mencionados acima, mesmo quando, se considera o receio na proposição dos objetos de conhecimento das aulas em relação à forma como estão sendo desenvolvidos, ressaltando que as práticas pedagógicas devem ser priorizadas em sua proposição.

A preocupação com a violência e agressividade foi também apontada em uma subcategoria das Características desfavoráveis dos professores no ensino das lutas (Quadro I). 
Esta preocupação relacionada com o estímulo à competitividade, à falta de ética por parte dos profissionais, o direcionamento para a violência e o excesso de rigidez e doutrina, identifica-se com cinco das 12 ocorrências dessa Categoria. Acredita-se que a preocupação com a violência e agressividade possa surgir na competição exacerbada, supervalorizando a vitória, imaginário produzido pela mídia, culminando no desenvolvimento do ensino das lutas baseado nesses pressupostos. Para Andraus (2013), a prática da arte marcial se constitui em ferramenta importante para o controle da agressividade, se realizada com atividades que propiciam ao indivíduo desenvolver o autoconhecimento.

O professor é responsável pela forma na qual as lutas terão impacto na vida dos alunos, por exemplo, ao se supervalorizar a vitória, o aluno expressa-se de forma competitiva com seus próprios colegas de treino, ocasionando a sua inibição em uma derrota, proporcionando uma cobrança de si mais do que o necessário, buscando a utilização de sua força acima da técnica, o que além de dificultar sua aprendizagem, pode levar a comportamentos mais agressivos. Da mesma forma, no caso do aluno vitorioso, quando supervalorizado poderá realmente se sentir superior e não compreender os aspectos educacionais propostos. Portanto, ao desejar a vitória a qualquer preço, os colegas de treino, que deveriam se enxergar como amigos, integrantes de um processo de aprendizagem, podem até mesmo se machucar e ter atitudes socialmente inadequadas nesta busca. A disputa e o desafio entre os alunos pode ser uma ocorrência comum em ambiente escolar como sinaliza Farias, Wiggers e Almeida (2019). As lutas ou lutinhas promovidas pelos discentes são configurações sociais que devem ser mediadas e ressignificadas a luz de uma intervenção pedagógica que oriente para ações mais produtivas. Nesse sentido, o professor tem papel de destaque na escola.

Portanto, se a prática esportiva na iniciação focar em resultados, tendo como modelo atletas de alto rendimento, com treinos semelhantes aos praticados por adultos, a exigência prematura às crianças da realização técnica com perfeição e eficiência em situações táticas complexas ocorrerá, buscando atender as demandas da competição com alto nível de exigência (BALBINO, et al., 2013). Como resultado, teremos a antecipação das fases do processo de aprendizagem esportiva, que pode gerar uma tensão e obrigatoriedade de treinamento, podendo levar ao abandono, por vezes precoce da prática esportiva. Para os autores, quando o processo didático-pedagógico não é respeitado, o aluno não será capaz de usufruir do esporte em sua pluralidade, proporcionando prazer pela prática esportiva, o que deve ser o objetivo de processo pedagógico no ambiente escolar.

Por outro lado, quando o professor valoriza as atitudes, os valores, a harmonia, o aprender junto, a amizade e companheirismo, a vitória se torna menos importante, somente uma questão de tempo e aprimoramento. A competitividade entre os alunos passa a ser diversão e uma forma de ajuda ao outro em seus erros, aprendendo juntos a sair de situações difíceis no momento da luta. Os colegas brincarão de lutar, e em diferentes momentos, alguns ganharão e ao final de cada luta, formas e saídas para cada situação serão descobertas, resultado de uma proposta pedagógica baseada em resolução de problemas objetivando a continuidade na prática, gerada pela motivação dos alunos no engagamento em modalidades de lutas corporais. 
Segundo um diretor:

Primeiro lugar a formação acadêmica, a formação com a didática que todos os docentes têm. Essa questão tem que ser bem clara para o professor das lutas, digo, a preocupação também com o que o moleque vai fazer lá fora, que ele não bote na cabeça da criança que ele é um 'cachorro de briga'.

De forma ampla, Almeida et al. (2016) destacam a importância do processo e formação e sua continuidade ao longo da atuação profissional para que o professor possa desempenhar de forma eficiente e atualizada. Galatti et al., (2007), afirmam que a formação profissional e pedagógica daqueles que atuam na iniciação esportiva é importante. Para o professor, além de conhecer a técnica, a tática, os aspectos físicos e métodos de aplicação, a fundamentação pedagógica é primordial, como conhecimentos sobre o desenvolvimento geral da criança, e elementos que possibilitem a compreensão do contexto sociocultural dos seus alunos, podendo então intervir construindo mudanças, e não impondo valores.

Em concordância, uma coordenadora apresenta:

O professor de qualquer área tem que saber lidar com a criança, ele tem que conhecer. É fundamental que esse professor conheça um pouco as características do desenvolvimento das crianças, pra não ter nenhum problema em relação à autoestima da criança. Fazer com que ela se sinta feliz nesse trabalho, e não exigida, de forma muito intensa. [...] da oportunidade dessas crianças nessa interação, elas se conhecerem melhor, ter controle sobre as emoções, com a ajuda desse professor.

Os dirigentes apresentam como características pessoais almejadas dos profissionais de lutas: ser ético, ter coesão, coerência e bom senso, educado, ser flexível e ter princípios. Reafirmado por uma coordenadora:

[...] posso dizer pra você que seria muito agradável que esse professor de lutas tivesse uma resiliência bacana, uma pessoa extremamente flexível, uma pessoa primordialmente educada, não educada só de uma boa formação acadêmica, em um colégio particular, mas educada de berço, de princípios. Esses pra mim são as necessidades básicas pra você atuar seja aonde for, não só como professor de lutas, mas que ele tenha dentro de si a capacidade de falar o sim e o não com o mesmo peso.

A categoria menos citada, mas, não menos importante, é da relação estabelecida entre o profissional de lutas e o contexto escolar, na necessidade de conhecer a proposta da escola, se integrando ao planejamento e objetivos pedagógicos, além de saber fazer registros e diários de classe, interagindo com a realidade na qual os projetos serão realizados. Quanto à prática pedagógica desenvolvida na escola, a preocupação deve ser direcionada ao alinhamento dos 
objetivos com o ambiente e o contexto nos quais estará inserida, com significância para os alunos. O contato com os outros atores da comunidade escolar se torna imprescindível para o respaldo no embasamento, na fundamentação e na criação de metas a serem atingidas, metas presentes no dia-a-dia dos alunos, com o conhecimento das dificuldades e desejos de todos. Segue o discurso de dois diretores:

[...] ele tinha que estabelecer uma parceria primeiramente dentro do conteúdo programático, dentro do currículo da unidade escolar. O que se espera como meta e objetivo.

Eu acho que deveriam ser formados grupos por faixa etária, o professor ter um compromisso pedagógico bimestralmente, ter começo meio e fim, começa no começo do ano e ter o projeto dele até dezembro, então ele vai conseguir bimestralmente ver o avanço e ser acompanhado por um coordenador pedagógico.

O professor deve objetivar muito além da formação de campeões e técnicas específicas, buscando o sentimento de bem-estar da vida dos educandos, para que possam viver em harmonia, sentindo-se como cidadãos plenos. Nesse sentido, o trabalho docente deve estar alinhado com as perspectivas da escola para uma formação integral do alunado. Cavazani et. al. (2016), afirmam que devemos dar atenção à sistematização e organização do processo de ensino e aprendizagem para que não acarrete a restrições das possibilidades de uma iniciação esportiva ampla. Tendo sempre em vista que a intervenção pedagógica, seja no esporte ou em qualquer outra área, configura-se em um processo formado de inúmeros sentidos e dimensões das atividades humanas que objetivam, sobretudo, uma ação centrada na educação. Considerando-se ainda a complexidade que envolve o ensino das lutas, em sua diversas manifestações e em diferentes ambientes, muita atenção deve ser dada à proposição de adaptações da prática pedagógica. Isso remete à ressignificar a prática, sem necessariamente incriminar e julgar outras, principalmente quando estão relacionadas a uma perspectica histórica e cultural, mas, buscar a transformação para o que se pretende, considerando suas intencionalidades e particularidades (RUFINO; DARIDO, 2012).

O reconhecimento das subjetividades dos alunos é fundamental para atuação em ambiente escolar, para que seja desenvolvida de forma apropriada e contextualizada. 0 professor deve conhecer muito além das técnicas das lutas, como sua história, a cultura subjacente, seus valores, seu potencial transformador e alternativas didáticas. A contextualização das lutas no ambiente e a diversificação dos objetivos e estratégias pedagógicas podem ocorrer, possibilitando que a emancipação seja então alcançada por todos no processo de ensino e aprendizagem, de forma respeitosa, promovendo a compreensão das manifestações em sua plenitude. Assim, esse profissional estará mais alinhado com as perspectivas dos profissionais atuantes na escola.

\section{Considerações Finais}


As lutas se inserem no contexto escolar, em primeiro lugar por fazerem parte da cultura corporal de movimento, desenvolvidas historicamente. Mas, também, por serem consideradas como objeto de conhecimento da educação física escolar e legitimada, como tal, pelos documentos oficiais e pela literatura acadêmica que versa sobre o tema. Neste contexto, o presente estudo buscou compreender as concepções sobre o perfil do professor de luta pelos dirigentes das escolas de Ensino Fundamental 1, do município de Jaguariúna (SP). Os dados nos apresentaram duas perspectivas distintas, porém, relacionadas: as concepções sobre o professor que ensina lutas na escola e o perfil desejado para esse profissional atuar em ambiente escolar.

Pode-se verificar a preocupação por parte dos dirigentes das escolas no que se refere ao conhecimento e formação pedagógica dos profissionais que trabalham ou desejam trabalhar na escola. Essa preocupação se consolida principalmente na falta de didática, de metodologia de ensino, de planejamento e de pedagogia em relação à formação geral desses profissionais. A prática das lutas na escola mostra-se como um importante objeto de conhecimento escolar, ambicionado pelos dirigentes que quando questionados, concordam com a inserção desta atividade e seu potencial educativo. O ambiente escolar mostra-se propício e favorece essa vivência, uma vez que é o lugar onde os discentes passam parte do tempo. Reforçamos a opinião dos dirigentes que, quando bem pensado, planejado e com um profissional qualificado e identificado com os objetivos da escola para uma prática pedagógica diferenciada, as lutas podem trazer inúmeros benefícios, não apenas como atividade física, mas também para a formação integral do aluno. Desta forma, propomos a realização de novas pesquisas que contemple desenvolver este objeto de conhecimento promovendo segurança para inserção no ambiente escolar, seja na educação físcia ou em projetos extracurriculares. Para que isso seja possível, sugerimos a formação de professores para realizarem intervenções, tendo como meta o desenvolvimento humano em toda a sua plenitude. Para tanto, a oferta de mais cursos de formação e aprimoramento pedagógico para profissionais de lutas voltados para o ambiente escolar se mostra uma proposta interessante, proporcionando uma ponte entre 0 conhecimento empírico e o saber pedagógico. Nesta proposta, o aluno deve ser o centro do processo de ensino e aprendizagem de forma que suas subjetividades sejam consideradas e a criatividade seja incentivada. Cabe ainda destacar as limitações do presente estudo no que se refere a seleção da amostra, que, apesar de contemplar todas as escolas com ensino fundamental 1 do município de Jaguariúna, não atinge outras regiões, que por conveniência dificulta a extrapolação dos achados e das conclusões, o que sugere a ampliação desse estudo em outras regiões e com amostras maiores. Entretanto, se pôde verificar uma aproximação dos achados com a literatura consultada..

\section{Referências}

ALMEIDA, P. D. B.; BARROS, H. F.; GEBRAN, R. A.; FRANCISCO, M. V. Formação continuada em serviço de professores de educação física de uma escola privada do interior do estado de São Paulo. Pensar a Prática, Goiânia, v.19, n.4, out./dez. 2016.
ANDRAUS, M. B. M. Arte marcial e agressividade. In: ANTUNES, M. M., IWANAGA, C. C. (Orgs.). Aspectos Multidisciplinares das Artes Marciais. Jundiaí: Paco Editorial, 2013. 
ANTUNES, M. M. Uma Breve Reflexão Sobre a História e as Funcionalidades das Artes Marciais na Contemporaneidade. In: ANTUNES, M. M., ALMEIDA, J. J. G. (Orgs.). Artes Marciais, Lutas e Esportes de Combate na Perspectiva da Educação Física: Reflexões e Possibilidades. Curitiba, PR: CRV, 2016a.

ANTUNES, M. M. A produção acadêmica em Lutas, Artes Marciais e Esportes de Combate: reflexões e possíveis encaminhamentos. Revista Brasileira de Prescrição e Fisiologia do Exercício. v.10, n.63, p.921-924, 2016b.

ANTUNES, M. M. Artes marciais para pessoas com deficiência: dilemas e possibilidades do wushu. Rio de Janeiro: Multifoco, 2016c.

AVELAR-ROSA, B.; GOMES, M.; FIGUEIREDO, A.; LÓPEZ-ROS, V. Caracterización y desarrollo del "saber luchar": contenidos de un modelo integrado para la enseñanza de las artes marciales y de los deportes de combate. Revista de Artes Marciales Asiáticas, v.10, p.16-33, 2015.

BALBINO, H. F.; GALATTI, L. R.; FERREIRA, H. B.; PAES, R. R. Pedagogia do Esporte: significados da iniciação esportiva e da competição. In: REVERDITO, R. S.; SCAGLIA, A. J.; MONTAGNER, P. C. Pedagogia do esporte: aspectos conceituais da competição e estudos aplicados. São Paulo: Phorte, 2013.

BARDIN, L. Análise de conteúdo. Lisboa: Edições 70, 2011.

BRASIL. Ministério da Educação. Base Nacional Comum Curricular (BNCC). Educação Física. Brasília: MEC/SEF, 2018. Disponível em: http://basenacionalcomum.mec.gov.br/images/BNC C EI EF 110518 versaofinal site.pdf Acessado em 18 de Novembro de 2019.

BREDA, M.; GALATTI, L.; SCAGLIA, A. J.; PAES, R. R. Pedagogia do esporte aplicada às lutas. São Paulo: Phorte, 2010.

CARREIRO, E. A. Lutas. In: DARIDO, S. C.; RANGEL, I. C. A. (Orgs.). Educação Física no Ensino Superior Educação Física na Escola: Implicações para a prática pedagógica. Rio de Janeiro: Guanabara Koogan, 2011.
CAVAZANI, R. N.; REVERDITO, R. S.; DRIGO, A. J.; SCAGLIA, A. J.; MONTAGNER, P. C.; PAES, R. R. Pedagogia do esporte: tornando o jogo possível no judô infantil. Motrivivência. v.28, n.47, p.177-90, 2016.

CORREIA, W. R.; FRANCHINI, E. Produção acadêmica em lutas, artes marciais e esportes de combate. Motriz. v.16, n.1, p.01-09, 2010.

DRIGO, A. J.; SOUZA NETO, S.; CESANA, J.; TOJAL, J. B. A. Artes marciais, formação profissional e escolas de ofício: Análise documental do judô brasileiro. Motricidade, v.7, n.4, p.49-62, 2011.

ESPARTERO, J. Aproximación histórico-conceptual a los deportes de lucha In: VILLAMÓN, M. Introducción al Judo. Barcelona: Editorial hispano Europea S.A., 1999.

FARIAS, M. J. A.; WIGGERS, I. D; ALMEIDA, D. M. F. "Não é briga, não... É só brincadeira de lutinha": cotidiano e práticas corporais infantis. Pensar a Prática, Goiânia, v.22, p.1-13, 2019.

GALATTI, L.; BREDA, M.; SCAGLIA, A. J.; PAES, R. R. Pedagogia do Esporte e Competição Infantil: análise e proposições a partir do Karatê de Contato. Movimento \& Percepção, v.8, n.11, p.169-85, 2007.

GOMES, M.; AVELAR-ROSA, B. Martial arts and combat sports in physical education and sport sciences degrees-a comparative study of Brazil, France, Portugal, and Spain. INYO-The journal of alternative perspectives on the martial arts and sciences, v.12, n.1, p.14-29, 2012.

GOMES, M. S. P.; MORATO, M. P.; DUARTE, E.; ALMEIDA, J. J. G. Ensino das lutas: dos princípios condicionais aos grupos situacionais. Movimento, v.16, n.2, p.207-227, 2010.

KOZUB, F. M.; KOZUB, M. L. Teaching Combative Sports through Tactics, Journal of Physical Education, Recreation \& Dance, v.75, n.8, p. 16-21, 2004.

LOURDES, L. F. C. Aspectos pedagógicos das lutas como linguagem corporal. In: NISTA-PICCOLO, V.; TOLEDO, E. (Orgs.). Abordagens pedagógicas do esporte: Modalidades convencionais e não convencionais. Campinas: Papirus, 2014.

LOURENÇO FILHO, A. O Ensino das Artes Marciais: Questões Pedagógicas. In: ANTUNES, M. M.; 
IWANAGA, C. C. (Orgs.). Aspectos Multidisciplinares das Artes Marciais. Jundiaí: Paco Editorial, 2013.

OLIVIER, J. C. Das brigas aos jogos com regras: enfrentando a indisciplina na escola. Rio de Janeiro: Editora Artmed, 2000.

PAES, R. R.; GALATTI, L. R.; REVERDITO, R. S. Lutas, Artes Marciais e Esportes de Combate: Reflexões a partir da Pedagogia do Esporte. In: ANTUNES, M. M., ALMEIDA, J. J. G. de (Orgs.). Artes Marciais, Lutas e Esportes de Combate na Perspectiva da Educação Física: Reflexões e Possibilidades. Curitiba: CRV, 2016.

RODRIGUES, A. I. C.; BAIÃO JUNIOR, A. A.; ANTUNES, M. M.; ALMEIDA, J. J. G. Percepção dos dirigentes das escolas do município de Jaguariúna sobre as lutas. Journal of Physical Education, v.28, n.1, 2809, 2017.

RUFINO, L. G. B.; DARIDO, S. C. Pedagogia do esporte e das lutas: em busca de aproximações. Revista Brasileira de Educação Física e Esporte. v.26, n.2, p.283-300, 2012.

RUFINO, L. G. B.; DARIDO, S. C. O ensino das lutas nas aulas de Educação Física: análise da prática pedagógica à luz de especialistas. Journal of Physical Education, v.26, n.4, p.505-518, 2015.

THOMAS, J. R.; NELSON, J. K.; SILVERMAN, S. J. Métodos de pesquisa em atividade física. 6ed. Porto Alegre: Artmed Editora, 2012.

Recebido em: 28/09/2019

Aceito em: 29/11/2019

Endereço para correspondência:

Alba Iara Cae Rodrigues

albaicrodrigues@hotmail.com

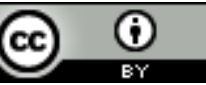

Esta obra está licenciada sob uma Licença Creative Commons Attribution 3.0 